\title{
Adrenaline Autoinjector Needle Interlocking in the Thumb Due to Im- proper Injection
}

\author{
Schmid $\mathrm{M}^{1, *}$, Weidenhoffer $\mathrm{I}^{1}$, Udvardi $\mathrm{A}^{1}$, Lomoschitz $\mathrm{K}^{2}$, Volc-Platzer $\mathrm{B}^{1}$ and Wöhrl $\mathrm{S}^{3}$ \\ ${ }^{1}$ Department of Dermatology, Donauspital, Vienna, Austria \\ ${ }^{2}$ Department of Radiology, Donauspital, Vienna, Austria \\ ${ }^{3}$ Floridsdorf Allergy Centre (FAZ), Vienna, Austria
}

\begin{abstract}
Herein, a case of improper epinephrine autoinjector injection into the thumb involving deep connective tissue and bone is reported. We additionally review knowledge, skills and habits of a cohort of autoinjector users of a hospitalbased dermatologic outpatient clinic.
\end{abstract}

Keywords: Epinephrine autoinjector, digital ischemia, application error.

\section{INTRODUCTION}

Accidental digital injection of epinephrine autoinjectors is a known side-effect when dispensing this units to patients suffering from anaphylactic reactions [1]. In this case story, we report a 42-year old man with hymenoptera venom allergy and a history of a systemic reaction. The patient had been evaluated in an outpatient allergy clinic. According to current guidelines [2], he had been equipped with an emergency medication, including an epinephrine autoinjector $\left(\right.$ EpiPen $\left.{ }^{\circledR}\right)$ for self-treatment of allergic reactions. He had been instructed in the proper use when he was issued the epinephrine autoinjector $\left(\right.$ EpiPen $^{\mathbb{B}}$ ) by a dermatologist, as according to a long-standing tradition, in Austria, patients with hymenoptera venom allergy are evaluated and treated by dermatologists.

After being stung by a yellow jacket one day, the patient experienced a sensation of impending collapse. He attempted to employ the autoinjector, but, after unlocking he gripped it upside down causing the needle to penetrate his right thumb's distal phalanx. Within minutes, the patient was brought to the emergency department by the emergency physician who had already administered intravenous antihist?mines and corticosteroids. On arrival, the patient had already recovered from the symptoms of an allergic reaction, but his thumb was found to be pale and cold with the autoinjector still stuck in the patient's thumb. An X-ray of the hand revealed the needle being located in the soft tissue, furthermore the tip of the needle had hit the bone and had been bent more than 90 degrees (Fig. 1a). Not only the mechanism had deployed as expected and injected the epinephrine dose into the thumb, but the needle stuck in the thumb acting as a barbed hook (Fig. 1b). By careful manoeuvering, controlled

\footnotetext{
*Address correspondence to this author at the Department of Dermatology, Donauspital, Vienna, Austria; Tel.: +43 1 28802-4102;

Fax: +43 1 28802-4180; E-mail: martina.schmid@wienkav.at
}

by sequential radiograms, the needle was removed. Subsequently, the patient received topical application of glyceryl trinitrate and concomitant oral administration of acetylsalicylic acid. Local infiltration of the $\beta_{2}$ agonist terbutaline, which had been suggested by the Vienna poison center, was refused by the patient. Finally, the impaired circulation could be restored. There was no permanent structural or functional damage observed in the further clinical course.

With our interest drawn to incorrect epinephrine autoinjector use, we made a short interview with a cohort of 19 patients diagnosed with hymenoptera venom allergy, attending our clinic for desensitization therapy with hymenoptera venom (Table 1). Over a period of three months, 17 of 19 interviewed patients were still carrying the autoinjector (Epipen $\left.{ }^{\circledR}\right)$ with them $(89.5 \%)$. In three of the remaining 17 cases $(17.6 \%)$ the autoinjector had expired, leaving 14 patients equipped with a well functioning autoinjector $(82.35 \%)$. We investigated whether the patients were still able to properly use a demonstrator autoinjector pen. Ten of 14 patients with a well functioning autoinjector (71.4\%) were capable to use the demonstration pen in a correct manner; in 4 cases the use was incorrect including one ectopic application, one application of too short contact duration (no injection triggered) and two incorrect applications for other reasons. The three patients with an expired autoinjector were not capable to demonstrate the autoinjector use in a correct way, including one ectopic application, one application of too short contact duration (no injection triggered), and one incorrect application of other reason (cap not removed and therefore no injection triggered).

Several cases of accidental injection of epinephrine autoinjectors into digits including the thumb have been published. The estimated incidence is about one accidental digital injection per 50000 autoinjector units [3]. Epinephrine causes vasoconstriction, the harmed digit is at risk for necrosis. Suggested treatment includes immersion in warm water, topical nitroglycerin, local injection of terbutaline [4] 


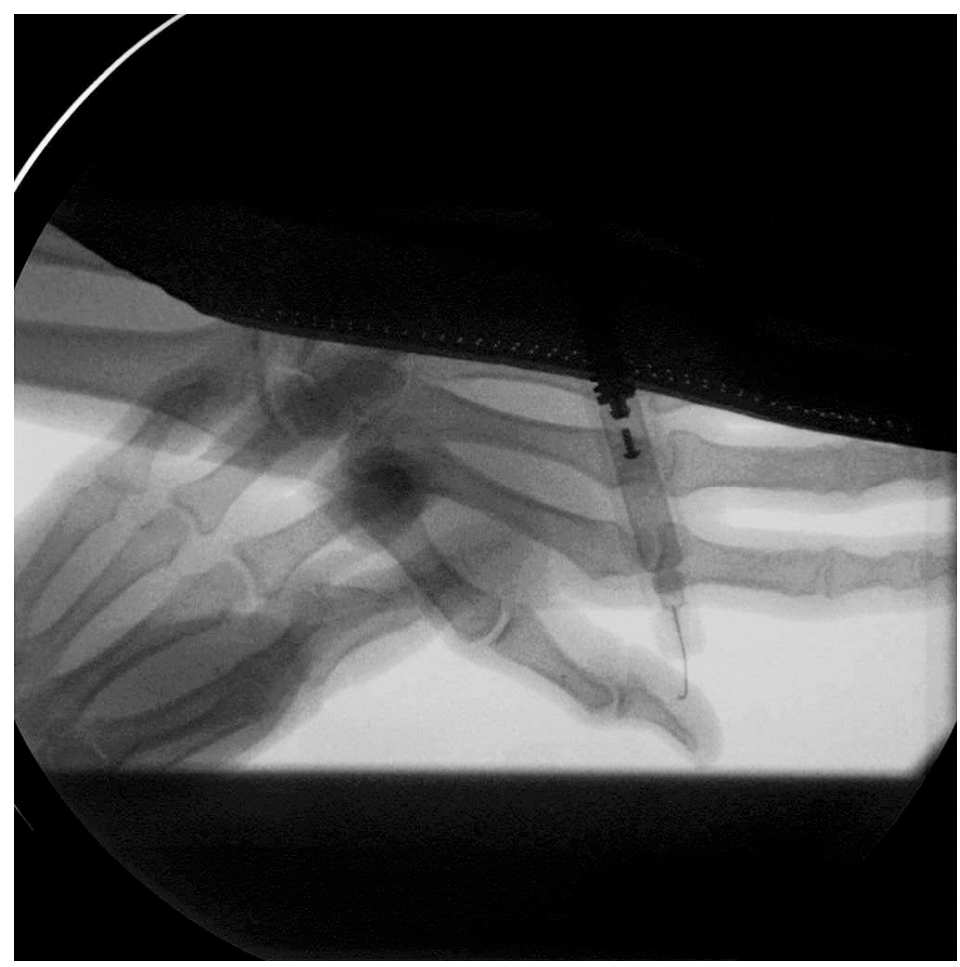

Fig. (1a). X-ray of the epinephrine autoinjector locked in the distal phalanx of the right thumb.

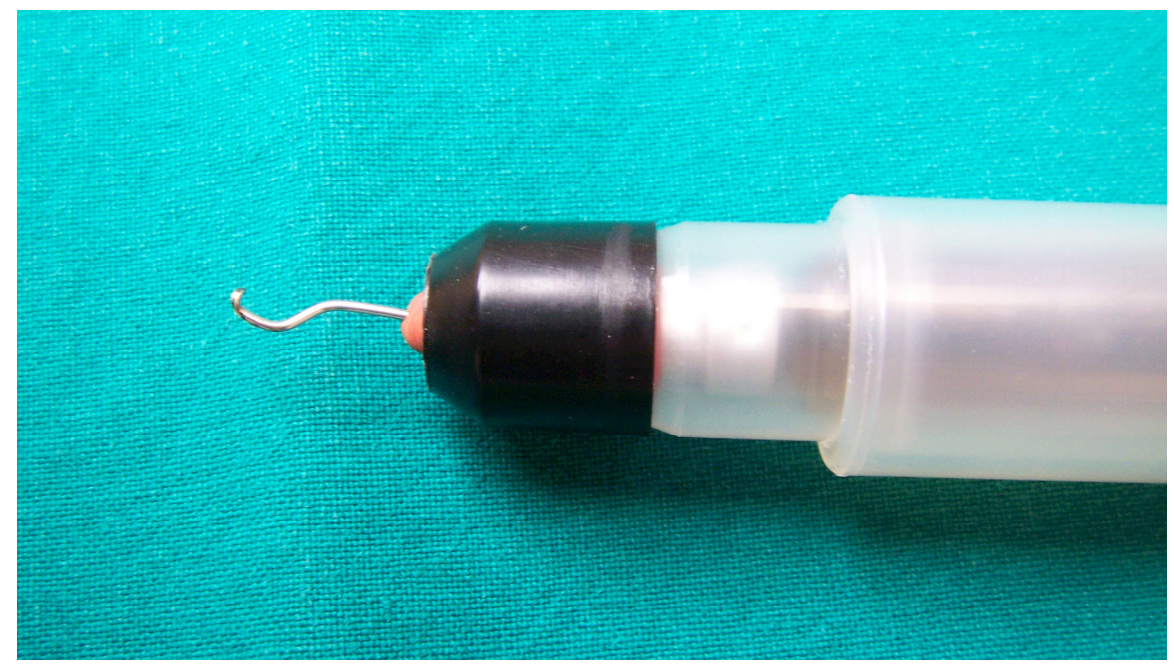

Fig. (1b). The distorted needle of the epinephrine autoinjector (Epipen ${ }^{\circ}$, ALK-Abelló, Linz, Austria) after removal from the thumb.

Table 1. Patient Characteristics and Test Results. Abbreviations: F: Functional Autoinjector, E: Expired Autoinjector, C: Correct Application, I: Incorrect Application, N: Autoinjector not Available

\begin{tabular}{|c|c|c|c|c|c|}
\hline Patient & Age & Sex & Allergy & Classification of Allergic Reactions [11] & Use of Training Device \\
\hline \hline 1 & 45 & $\mathrm{~m}$ & Yellow jacket & IV & II \\
\hline 2 & 38 & $\mathrm{~m}$ & Yellow jacket & IV & F,C \\
\hline 3 & 67 & $\mathrm{f}$ & Yellow jacket & IV & F,C \\
\hline 4 & 60 & $\mathrm{~m}$ & Yellow jacket & IV & F,I \\
\hline 5 & 56 & $\mathrm{f}$ & Yellow jacket & IV & E,I \\
\hline 6 & 67 & $\mathrm{f}$ & Honeybee, Yellow jacket & II & F,C \\
\hline 7 & 62 & $\mathrm{f}$ & Yellow jacket & & \\
\hline
\end{tabular}


Table 1. contd....

\begin{tabular}{|c|c|c|c|c|c|}
\hline Patient & Age & Sex & Allergy & Classification of Allergic Reactions [11] & Use of Training Device \\
\hline 9 & 64 & $\mathrm{f}$ & Yellow jacket & III & $\mathrm{F}, \mathrm{I}$ \\
\hline 10 & 63 & $\mathrm{f}$ & Yellow jacket & II & $\mathrm{N}$ \\
\hline 11 & 72 & $\mathrm{f}$ & Yellow jacket & IV & $\mathrm{F}, \mathrm{C}$ \\
\hline 13 & 76 & $\mathrm{f}$ & Yellow jacket & II & E, I \\
\hline 14 & 26 & f & Yellow jacket & II & E,I \\
\hline 15 & 66 & $\mathrm{~m}$ & Yellow jacket & III & $\mathrm{N}, \mathrm{C}$ \\
\hline 16 & 41 & $\mathrm{f}$ & Yellow jacket & IV & $\mathrm{F}, \mathrm{C}$ \\
\hline
\end{tabular}

or phentolamine [5]. In all published cases, no case of digital loss or other permanent damage was observed, irrespective of treatment. A retrospective cohort study on cases reported to six poison centers during six years found 365 epinephrine injections to the hand, of those, 213 were digital injections. All patients showed no significant systemic effects and complete resolution of symptoms [1]. Even in untreated patients, no necrosis or skin loss was described [5].

In our interview series, $89.5 \%$ of a cohort of 19 recently instructed patients were still carrying their autoinjector with them. $71.4 \%$ of our examined patients were capable to use the training device in a correct manner. In a study by DeMuth et al [6], only 37/63 food allergic-children were still carrying the prescribed autoinjector. In another study of 96 patients with insect venom allergy, less than $30 \%$ carried the autoinjector at all times and only $44 \%$ of patients were able to demonstrate proper autoinjector administration technique [7]. In a recently published study by Brown et al. [8], 15\% of mothers without previous epinephrine autoinjector knowledge or experience could not "fire" training devices correctly despite a prior one-to-one demonstration of 30 minutes duration. Only $22 \%$ of mothers were able to perform all ten procedures according to predetermined criteria used to assess the mother's performance in using a randomly assigned epinephrine autoinjector device following a standardized teaching session by one clinician.

In another study by Topal et al. [9], 59/64 patients (14 children with food or venom allergy and 50 caregivers) obtained the autoinjector device after initial prescription. 42 (71\%) still had the device at the time of the study. $54.6 \%$ of patients were not having an autoinjector because they felt that it was no longer necessary. There was a significant relation between adrenaline autoinjector competency and regular visits to the allergist. Autoinjector competency decreased as time elapsed from the last visit and the first instruction.

Arga and colleagues [10] demonstrated the importance of autoinjector design on unintentional injection injury. They compared a new and an originally designed epinephrine autoinjector with respect to correct use by 180 interns of the 2011-2012 training period of the medical school, randomly assigned into two groups. The number of participants correctly showing the use of epinephrine autoinjectors did not differ significantly between the two groups, but significantly fewer participants had unintentional injections in the new compared with the old epinephrine autoinjector group $(p<$ 0.001). They concluded that the new epinephrine autoinjector was more effective in avoiding unintentional injection injuries than the old one; however, it still did not fulfill the criteria of an ideal epinephrine autoinjector.

Overall, our observational study in accordance with previously published studies demonstrated that the compliance of carrying autoinjectors at all times and the ability of correct administration were poor and needed optimization.

In conclusion, a continuous, repetitive instruction of correct epinephrine autoinjector use by health care professionals is required.

\section{CONFLICTS OF INTEREST}

The authors confirm that this article content has no conflicts of interest.

\section{ACKNOWLEDGEMENTS}

Declared none.

\section{REFERENCES}

[1] Muck AE, Bebarta VS, Borys DJ, Morgan DL. Six years of epinephrine digital injections: absence of significant local or systemic effects. Ann Emerg Med 2010; 56: 270-4.

[2] Bonifazi F, Jutel M, Bilò BM, Birnbaum J, Mueller U. Prevention and treatment of hymenoptera venom allergy: guidelines for clinical practice. Allergy 2005; 60: 1459-70.

[3] McGovern SJ. Treatment of accidental digital injection of adrenaline from an auto-injector device. J Accid Emerg Med 1997; 14: 379-80.

[4] Stier PA, Bogner MP, Webster K, Leikin JB, Burda A. Use of subcutaneous terbutaline to reverse peripheral ischemia. Am J Emerg Med 1999; 17: 91-4. 
[5] Fitzcharles-Bowe C, Denkler K, Lalonde D. Finger Injection with High-Dose $(1: 1,000)$ Epinephrine: Does it Cause Finger Necrosis and Should it be Treated? Hand 2007; 2: 5-11.

[6] DeMuth KA, Fitzpatrick AM. Epinephrine autoinjector availability among children with food allergy. Allergy Asthma Proc 2011; 32 (4): 295-300.

[7] Goldberg A, Confino-Cohen R. Insect sting-inflicted systemic reactions: attitudes of patients with insect venom allergy regarding after-sting behavior and proper administration of epinephrine. J Allergy Clin Immunol 2000; 106(6): 1184-9.
[8] Brown J, Tuthill D, Alfaham M, Spear S. A randomized maternal evaluation of epinephrine autoinjection devices. Pediatr Allergy Immunol 2013; 24: 173-7

[9] Topal E, Bakirtas A, Yilmaz O, et al. A real-life study on Acquired Skills from Using an Adrenaline Autoinjector. Int Arch Allergy Immunol 2013; 160: 301-6

[10] Arga M, Bakirtas A, Topal E, et al. Effect of epinephrine autoinjector design on unintentional injection injury. Allergy Asthma Proc 2012; 33(6): 488-92

[11] Mueller HL. Diagnosis and treatment of insect sensitivity. J Asthma Res 1966; 3: 331-3.

Received: March 07, 2013

(C) Schmid et al.; Licensee Bentham Open.

This is an open access article licensed under the terms of the Creative Commons Attribution Non-Commercial License (http://creativecommons.org/licenses/by-nc/3.0/) which permits unrestricted, non-commercial use, distribution and reproduction in any medium, provided the work is properly cited. 